NATALIA JUAN

GARCÍA

JESÚS PEDRO

LORENTE LORENTE
Profesora Titular del Departamento de Historia del Arte, Universidad de Zaragoza natajuan@unizar.es

Catedrático del Departamento de Historia del Arte, Universidad de Zaragoza jpl@unizar.es

\title{
Procesos artísticos participativos y colaborativos en los distritos culturales de Burdeos y Nantes
}




\section{PARTICIPATORY AND COLLABORATIVE ARTISTIC PROCESSES IN THE CULTURAL DISTRICTS OF BORDEAUX AND NANTES}

\section{ABSTRACT}

This paper analyses the burgeoning impulse, in the main cultural districts of Bordeaux and Nantes, of participative and collaborative art practices. Such adjectives are not synonymous but, true enough, it is sometimes difficult to differentiate these two categories of relational art; moreover, co-working spaces could literally be considered another kind of collaboration process. All in all, beyond terminology matters, the aim of this essay is to point out the flourishing of combined official and community-based initiatives. A model of arts-led urban revitalisation seeking greater involvement of the local ecosystem shaping a "cultural district", as alternative to the paradigm of the singular institutional trigger worldly identified with the Guggenheim-Bilbao. Nowadays there are many counter-examples in Bilbao and in French cities on the Bay of Biscay.

\section{Keywords}

Cultural districts; urban boosters; participative/collaborative art practices; public space

\section{RESUMEN}

Este artículo analiza el prolífico impulso en los principales distritos culturales de Burdeos y Nantes del arte participativo y colaborativo. Tales adjetivos no son sinónimos, pero es cierto que a veces es difícil diferenciar estas dos categorías de arte relacional; por otro lado, los espacios de co-working podrían ser designados, al pie de la letra, como otro tipo de proceso de co-laboración. Con todo, más allá de la terminología, lo que pretende esta reflexión es constatar el florecimiento de iniciativas oficiales y de base comunitaria combinadas. Un modelo de revitalización urbana a través de las artes con mayor involucración del ecosistema local formando un "distrito cultural", como alternativa frente al paradigma del singular detonante institucional mundialmente identificado con el Guggenheim-Bilbao. Hoy día no faltan los contraejemplos bilbaínos y en ciudades francesas del golfo de vizcaya.

\section{Palabras clave}

Distritos culturales; dinamizadores urbanos; prácticas artísticas participativas/colaborativas; espacio público 
1 INTRODUCCIÓN: modelos de ida y vuelta, entre el star system y el artivismo colectivo

Se ha hablado mucho del "milagro Guggenhein" en referencia al espectacular impacto del famoso museo inaugurado en 1997, en realidad "buque insignia" de un amplio programa de revitalización en Bilbao y su ría con otras muchas actuaciones anteriores que también han continuado años después, bajo muy diversas formas. Reclamos adicionales mundialmente famosos de la oferta cultural bilbaína han sido los encargos a arquitectos estrella y a artistas de renombre internacional. Este tipo de inversión cultural identificada con un enfático despliegue visual de obras firmadas por nombres célebres ha acaparado el mayor protagonismo en los debates y publicaciones sobre la repercusión del arte en la regeneración urbana, económica, cultural y social. Tal resonancia mediática sin duda ha producido un impresionante efecto de emulación en casi todas partes, empezando por las urbes más cercanas. Sin embargo, también están surgiendo contra modelos, incluso en geografías muy próximas, como es la costa atlántica francesa, donde algunas ciudades han preferido, desde los inicios de sus procesos de revitalización, conjugar el consumo cultural de productos estelares consagrados por el mercado artístico internacional con un semillero de iniciativas de base. Esta circunstancia ha abonado el crecimiento de muy diversas prácticas artísticas asociativas, colaborativas y participativas. Sin pretender una panorámica comparativa general, que requeriría muchas más páginas, nos interesa destacar en este breve ensayo la exitosa estrategia de Burdeos y Nantes. Ambas ciudades combinan apuestas emanadas del poder con iniciativas impulsadas desde abajo y además concentradas especialmente en determinados epicentros urbanos etiquetados como "distritos culturales". Es otro rasgo común que también comparten ya con Bilbao, siendo además muy abundantes otras similitudes, que se podrían sintetizar en:

- Un marcado pasado industrial, cuya reconversión socio-económica ha destacado focos de revitalización urbana.

- El río, el estuario, la ría, en definitiva, el waterfront como eje vertebrador territorial, combinando un corredor verde y animación artística.

- Clusters ribereños animados por la concentración de artistas, arte público y establecimientos vinculados a las artes.

La transformación de la decadente zona portuaria e industrial de Burdeos en un animado distrito cultural fue impulsada a partir de los años setenta, por altas instancias políticas, que abrieron en un vasto almacén de la zona franca, el CAPC, flamante centro de arte contemporáneo refundado como museo en 1983 y reabierto en 1990 tras una nueva remodelación. La fundación en el año 2000 del Museo des Chartrons, inaugurado en 2008 como Museo del Vino y del Negocio de Burdeos, sirvió de antesala a un proyecto mucho más ambicioso, La Cité du Vin. Desde su apertura en 2016 ha marcado un hito en el vecindario con su espectacular arquitectura convertida en enseña del "distrito cultural de Chartrons", nombre debido a la presencia histórica de un antiguo convento de la orden de los cartujos, que sigue marcando la identidad del barrio, ahora muy connotado por la efervescencia del sector creativo (Juan García, 2016). Su éxito ha llevado, en una ciudad de urbanismo expandido como Burdeos, a tomar también la denominación de "distrito cultural" en otros barrios de la ciudad, como el de la Bastide y el Euroatlantique, como hubs culturales cuyos buques insignia son respectivamente el Espace Darwin y la Maison de l'Economie Créative et de la Culture en Aquitaine (MECA). 
En Nantes la denominación asignada al corazón de su revitalización urbana comenzó a identificarse en 2006 bajo la designación temporal de Campus des Arts y se hizo oficial en 2009 cuando la corporación municipal lanzó el proyecto de Quartier de la Création, que se institucionalizó en 2011 al empezar a funcionar el conglomerado llamado Fabrique Urbaine et creative de l'île de Nantes $^{1}$. Desde entonces la zona occidental de la isla, antes célebre por sus astilleros y naves portuarias, es habitualmente conocida como "distrito de la creación". ${ }^{2} Y$ efectivamente, haciendo justicia a ese nombre, hoy este entorno es un auténtico hervidero artístico que reagrupa a múltiples creadores y establecimientos, confiriendo una personalidad especial a esa parte de la ciudad. No es de extrañar que la idea se haya replicado en otras ciudades francesas. Aunque quizá el culmen de la irradiación de este paradigma se alcanzara al ser creada en 2013 la designación "Bilbao Art District", referida al arte público, galerías de arte y museos u otros agentes culturales además del Guggenheim, con la colaboración de la Diputación Foral de Bizkaia y los museos, galerías, u otros espacios de producción artística en la ciudad. Así pues, ha habido en el litoral del Golfo de Vizcaya un flujo y reflujo de influencias que en definitiva han ido redefiniendo modelos híbridos de revitalización cultural.

En lugar de un expeditivo impulso emanado desde arriba protagonizado por la alta cultura y especialmente por magnas instituciones que produzcan un rápido impacto económico y urbanístico, se ha ido desarrollando en las urbes de la costa atlántica francesa otro modelo vitalizador de "cocción lenta" al calor de múltiples consorcios público-privados. Parece evidente que, en vez de la oposición o la mutua ignorancia entre el sector artístico y las instancias políticas, la tendencia actual en estos tiempos de crisis es incentivar procesos de revitalización urbana que ya no se inspiran tanto en el "efecto Guggenheim". Efectivamente, Nantes podría servir como su contraejemplo, pues siempre ha tenido a gala no seguir aquel modelo, sino poner en valor el legado patrimonial histórico y la cultura local e instigar un amplio espectro de intervenciones artísticas que resultan paradigmáticas de las más recientes categorías terminológicas en la involucración social del arte (Grau, Juan y Lorente, 2021). Si la típica culminación de un viaje cultural a Bilbao sería visitar en el Guggenheim alguna exposición de un artista de fama mundial, el más mediático reclamo turístico nantés es un divertido robot-elefante que pasea cargado de personas cuyas muecas y exclamaciones son parte del espectáculo, como también forman parte del show los ciudadanos de a pie que les abren paso e interaccionan con sus voces, fotos y gestos (Figura 1). Obviamente, esta antítesis es una simplificación extrema, aunque en el fondo no deja de ser muy reveladora del acendrado gusto francés por el arte contemporáneo "relacional", incluso en cuestiones de política cultural no mencionadas en el famoso libro de 1998 con el que Nicolas Bourriaud consagró ese epíteto. Mucho antes ya era habitual en Francia que las intervenciones artísticas en espacios públicos diesen especial protagonismo a performers e incluso al teatro de calle $u$ otras manifestaciones pomposamente designadas les arts de la rue, mientras que a este lado de la frontera se continuaba dando primacía a la estatuaria monumental. 


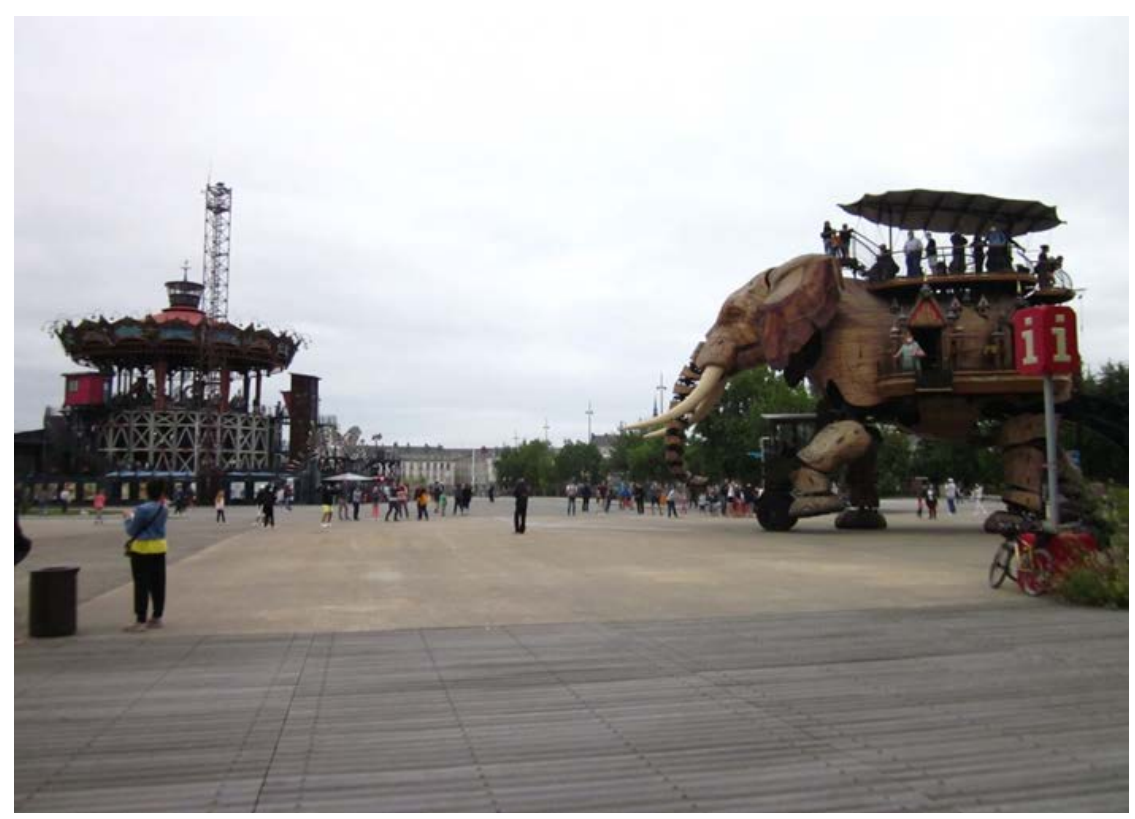

Figura 1. Instante en el que el Grand Éléphant pasea por la explanada des Chantiers Navals. Foto: Natalia Juan

Hay excepciones que confirman la regla, pues junto a la fachada del Guggenheim el museo tiene instalada desde 2014 una obra de carácter participativo, el Árbol de los deseos para Bilbao, con el que Yoko Ono invita a los viandantes a compartir con el mundo sus deseos de paz. Se trata de una de las versiones que desde 1996 la viuda de John Lennon ha ido instalando a las puertas de muchos museos y centros de arte por todo el orbe. Pero ese arbolito pasa bastante desapercibido en comparación con la popularidad del gigantesco perro floral de Jeff Koons, la colosal araña de Louise Bourgeois u otras obras de la propia colección del Guggenheim colocadas en su exterior, complementadas con las esculturas de un elenco de artistas célebres en el llamado Paseo de la Memoria inaugurado a finales de marzo de 2003. Por su parte, tampoco faltan ejemplos de arte público monumental en el Quartier de la Création de Nantes como los grandes Anneaux de Daniel Buren; pero encontraremos allí menos magnificación del artista genial individual en las intervenciones artísticas urbanas ligadas entre sí y con la ciudad por una línea verde. En general es muy común en las ciudades del arco atlántico francés el arte público participativo o colaborativo y la animación cultural vinculada al asociacionismo, lo cual otorga especial vivacidad social a sus distritos culturales. 
Las prácticas participativas que involucran a las audiencias en espacios urbanos comenzaron a desarrollarse en Francia a partir de espléndidos antecedentes históricos como el teatro de calle, que era en origen la especialidad de la compañía Royal de Luxe, fundada en 2004 por Jean Luc Courcoult, con sus imaginativos personajes articulados con los que han dinamizado todo tipo de públicos tanto en Nantes como en otras ciudades. El Grand Éléphant es un enorme robot que, desde su estreno en la bienal Estuaire de 2007, constituye una de las más animadas atracciones lúdico-culturales, tanto para quienes pagan por subirse a él como para los demás (Caro, 2012, p. 135). Su creador es François Delarozière, director artístico de la compañía de escenografías robóticas La Machine ${ }^{3}$, que luego ha creado otros animales mecánicos -incluido un camaleón gigante de dos metros de largo y 150 kilos- de gran éxito para desfilar en grandes celebraciones. La doble peculiaridad de esta "cabalgata" es, por un lado, que no se trata de un espectáculo efímero, pues a lo largo de los meses sigue atrayendo muchísimos visitantes a la ciudad bretona, concretamente a los antiguos talleres de la naviera Dubigeon en l'île de Nantes, donde, por otro lado, además de este espectáculo lúdico se programan actividades educativas, con todo tipo de explicaciones, que son parte de una amplia oferta patrimonial denominada Les Machines de l'île $e^{4}$ (Figura 2). En esas naves, donde se conservan los principales artilugios, también se puede ver -aunque no fotografiar por cuestiones de propiedad intelectual industrial- cómo se fabrican otros nuevos modelos en desarrollo que se han ido montando desde 2011. Es el caso del Carrousel des Mondes Marins, un triple tiovivo de fantásticas iconografías marítimas, alusivas a la historia portuaria y colonial nantesa e inspiradas en relatos del escritor Julio Verne.

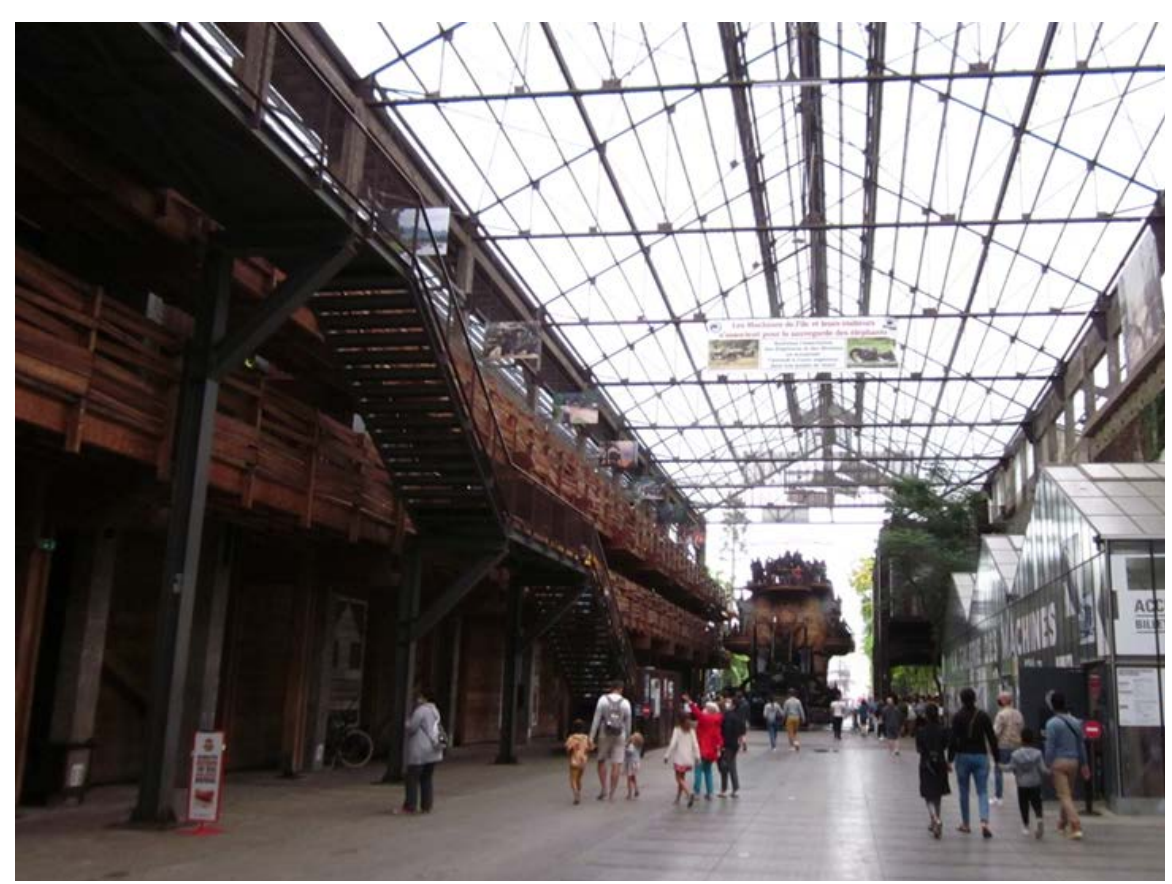

Figura 2. Las naves donde se encuentran los talleres de les machines de l'île en las que se diseñan los animales robots algunos de los cuales se visitan en la galería. Foto: Natalia Juan 
Se trata de un ejemplo para-museal digno de nuestra consideración porque representa la oferta turística y cultural más famosa del Quartier de la Création de l'île de Nantes, financiado con inversiones públicas y privadas precisamente con el objetivo de generar otra manera de "hacer ciudad" no dominada por la especulación urbana y los intereses particulares (Nicolas y Roy, 2015). Es un cluster de iniciativas mixtas lideradas fundamentalmente a través de una empresa pública denominada SAMOA -acrónimo de la Société d'Aménagement de la Métropole Ouest Atlantique-creada en 2003, que también realiza encargos a artistas y otorga subvenciones a las artes con un criterio social. Esta institución prioriza los proyectos que procuran la accesibilidad para los ciudadanos, fomentando la participación activa de los nanteses y la implicación de todos los que tengan inquietudes artísticas y culturales. ${ }^{5}$ Así, "esta convivencia de creadores y estudios ha favorecido que el arte urbano haya pasado a ser una realidad cotidiana de este ecosistema cultural, en la que la sucesión de todo tipo de actividades a lo largo del año puede leerse como una manifestación de la normalización que ha alcanzado dentro de la escena cultural nantesa" (Grau, Juan y Lorente, 2021, p. 25).

No es pues casual que ese ideal participativo caracterice muchas de las intervenciones de arte público ubicadas en l'île de Nantes que dan un giro irónico a equipamientos deportivos, con los que podemos interactuar inventando otras reglas de juego, como el Arbre à basket de la Agencia A/LTA formado por varias canastas de baloncesto superpuestas a modo de árbol en las que padres e hijos lanzan balones a la vez desde varios puntos diferentes (Figura 3). Es también el caso del parque de juegos titulado On va marcher sur la lune, obra de Bruno Peinado y Detroit Architects en el que se puede saltar sobre unos cráteres que evocan la superficie lunar y permite contemplar el planeta azul suspendido, o La Colline de Appelle-moi Papa, sita dentro de la Cantine du Voyage donde cualquiera que tenga entre 3 y 77 años puede correr y deslizarse, incorporando elementos netamente participativos. $Y$ en otros distritos de la ciudad hay adicionales instalaciones artísticas no menos divertidas e interactivas, pero sería una inapropiada digresión referirnos a ellas u otras semejantes en otras partes del mundo, pues lo que aquí importa es que éstas se agrupan en un distrito cultural.

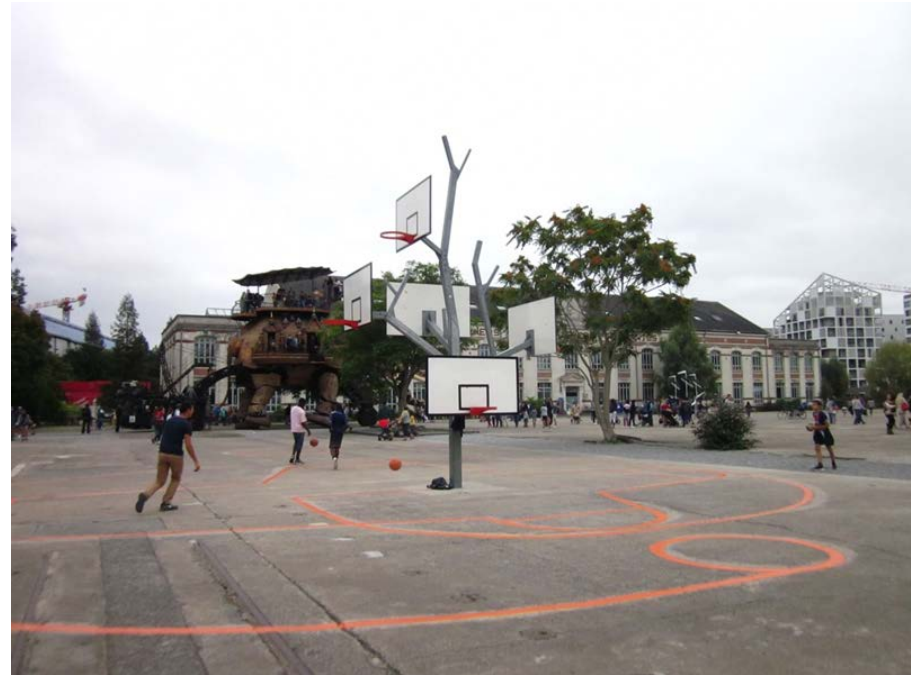

Figura 3. Imagen de la instalación titulada Arbre à basket de la Agencia A/LTA en la explanada des Traceurs de Coques en la ìle de Nantes. Al fondo el Grand Éléphant camino al Carrousel des Mondes Marins. Foto: Natalia Juan. 
En el Quartier de la Création de Nantes también hay intervenciones que mezclan la apariencia insólita con el uso comunal utilitario, según los principios del new genre public art, como la obra firmada por el atelier Van Lieshout titulada L'Absence. Se trata de una instalación con múltiples protuberancias sin ninguna delimitación ni función aparente por su aspecto externo, aunque dentro de ella se genera un espacio previsto como lugar de encuentro e interrelación social. De hecho, en su interior se abrió un bar que aspira a ser foco de intercambio de opiniones sobre la arquitectura actual. Algo como lo que ocurre también en otras esculturas-edificio que están dentro del recorrido de la línea verde en l'île de Nantes y muy cercanas. Todas son puntos de reunión accesibles para que se sienten personas a hablar: como es el caso de la Cannadienne del colectivo Fichtre, una divertida tienda india de madera que se usa como restaurante. Muy próximos estaban en su momento los poliedros de La pointe noire de Studio Katra habilitados para albergar a los clientes de una cafetería.

Eminentemente participativa, de un modo diferente, es también la dinámica de interacciones humanas a través del arte desarrollada en Burdeos bajo la denominación Courts-Circuits (Figura 4). Una propuesta inspirada literalmente en la famosa frase del escritor André Malraux "El arte es el camino más corto de hombre a hombre". La idea nació en la mente del artista bordelés Rouge quien quería producir una exposición itinerante fuera del elitista contexto del white cube. Los amantes del arte se convierten en representantes de una obra original que se les cede en préstamo durante un periodo de tiempo. Para participar, la primera condición es que los solicitantes a quienes se les presta la obra deben vivir en Burdeos y la segunda es que literalmente deben sacar a pasear al espacio público esa pieza artística "bajo el brazo" al menos una vez al mes cada semestre. Durante sus caminatas, los prestatarios actúan como "representantes" de la obra y deben hablar con/sobre ella a los viandantes que se encuentran, para lo cual disponen de un manual que, a modo de guía, les sugiere cómo comunicarse a través del arte. Rouge contó con el respaldo de Stéphane Carricondo, director artístico de la Fondation Desperados pour l'Art Urbain ${ }^{6}$ cuya valoración entusiasta se basó precisamente en el carácter participativo del proyecto, pero también en su innovadora forma de reformular el sistema del arte y sus relaciones humanas, poniendo en cuestión su base comercial. Sin embargo, irónicamente, también ha sido crucial la participación de galerías de arte de Burdeos como Magnetic ArtLab, cuyas paredes se vacían cuando sus obras son prestadas a los solicitantes que las sacarán de paseo. En definitiva, esta forma de pignoración deja suspendida en un limbo jurídico toda especulación sobre el valor de mercado del arte e incluso el sentimiento de posesión o de pertenencia. El contrato de préstamo para uso prevé que en caso de que el signatario ya no quiera la obra, será libre de devolvérsela al artista que la creó. Si opta por lo contrario, puede disfrutarla hasta el final de su vida, y la noción legal de préstamo se vuelve utópica, casi poética. El vínculo entre artista y amante del arte se torna diferente, casi anti-sistema, rompiendo con los usos establecidos.

Otra iniciativa próxima de arte relacional tuvo lugar entre el distrito cultural de Chartrons y el centro urbano de Burdeos en octubre de 2009, en el marco del festival Evento de la mano del japonés Tadashi Kawamata, quien también gusta siempre de trasponer y cuestionar las estructuras del sistema artístico. Consistía en una pasarela de madera dividida en dos tramos diseñada para conectar la enorme plaza des Quinconces con el quai fluvial, puesto que este espacio urbano se halla separado de la ribera por el tráfico rodado que impone un obstáculo físico y visual en la relación de la trama urbana con el río. Se daba a los paseantes la posibilidad de establecer una conexión física, visual y mental entre la ciudad y la orilla con una pasarela peatonal, de ahí el título de su instalación, Footpath, que ofrecía sobre el Garona un nuevo punto de vista del paisaje circundante y en general de la ciudad, creando también un puente 
social. Porque no solo se consiguió conectar dos orillas separadas, sino que se buscaron otras conexiones con la historia local, pues la materia prima con la que se construyó esta pasarela procedía al menos parcialmente del pino marítimo destrozado en la inundación y la tempestad que asoló la costa de las Landas en el invierno de 2009. Este recuerdo y otros comentarios que afloraron en los usuarios cargaron de significado en la memoria colectiva una instalación temporal de carácter fenomenológico y participativo, pues solo cobraba pleno sentido mientras el público la transitaba durante el año en que estuvo operativa. Además, como suele ser habitual en las obras de este artista, su construcción fue un proceso de trabajo colaborativo puesto que se llevó a cabo a través de un taller en el que participaron alumnos de la Escuela de Paisaje de Burdeos ${ }^{7}$.
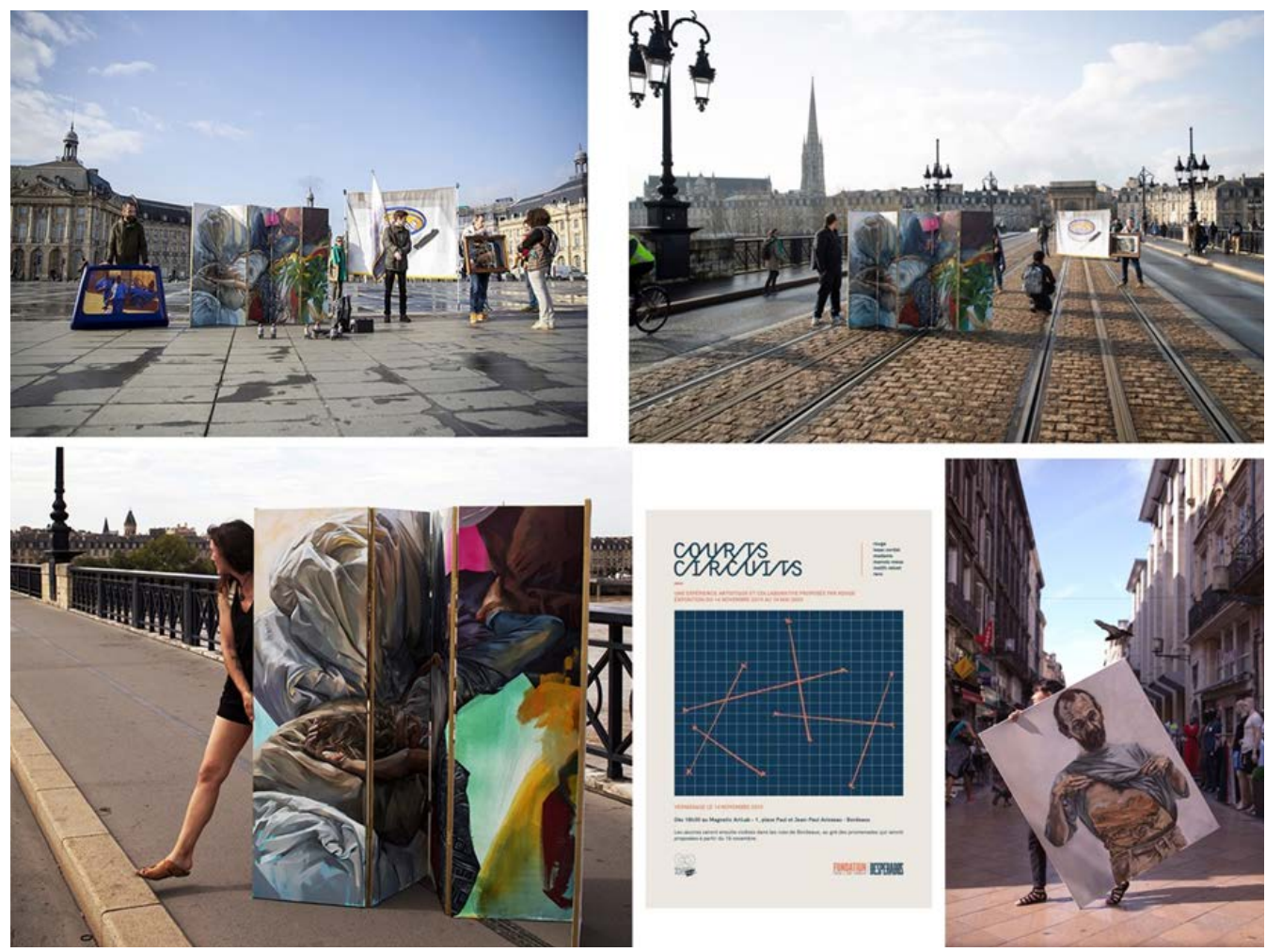

Figura 4. Imágenes del proyecto Courts-Circuits desarrollado en Burdeos como una experiencia artística participativa. Foto: Fundación Desperados.

\section{PRÁCTICAS COLABORATIVAS Y CO-WORKING, CODO CON CODO}

No ha sido un lapsus. Cuando hemos calificado de "colaborativo" el trabajo de Kawamata con los estudiantes de paisajismo bordeleses es porque Footpath es arte participativo, pero también fruto de una labor colectiva. Es un modus operandi muy propio de este artista nipón, igualmente presente en otras ciudades del arco atlántico francés, con obras semejantes como L'Observatoire, construida con la colaboración de la ciudadanía en Lavau sur Loire para la edición Estuaire Nantes-Saint-Nazaire del año 2007. Dicho proyecto se configura a partir de 
una torre y pasarela de madera, el mismo material que este autor utilizó para la edición de Le Voyage à Nantes de 2019 en su famoso Belvédère de l'Hermitage, desde el cual se domina una panorámica de l'île de Nantes. Estas instalaciones son difíciles de clasificar, ya que van más allá del "arte participativo" en espacios públicos (Bishop, 2012). Más bien habría que definirlas como "creación conjunta" según los criterios del propio artista, quien sostiene que deben considerarse como de autoría colectiva. Desde el momento en que una instalación coordinada por él ha sido realizada por otros es un proyecto de todos, se convierte en una obra "pública" en todos los sentidos de la palabra. La aspiración de Kawamata es que exista una correlación equilibrada entre el artista, la instalación y la gente que toma parte de forma intelectual y física en sus obras, compartiendo el proceso de creación artística y haciendo entre todos el esfuerzo de la ejecución de su materialización (Juan, Grau y Lorente, 2020, p. 80-83). Por eso, Tadashi Kawamata no consta ni como director artístico ni siquiera como coordinador, sino como un miembro más de la comunidad donde el trabajo colectivo se realiza sin jerarquías. Esto impide, entre otras cosas, la comercialización personal de sus producciones por ser de autoría múltiple y producto de un equipo.

Algo similar ocurre también con muchos de los proyectos de street art en l'île de Nantes, que son en buena medida participativos, porque involucran a la población, y sobre todo colaborativos pues están realizados de forma colectiva. Ejemplo paradigmático son las figuras inspiradas en la historia de la ciudad pintadas al lado del Hangar à Bananes, en una de las naves ubicadas en el sector del Parc des Chantiers, cuyos muros de grandes dimensiones decoró en 2015 Studio Katra junto con el artista nantés Ador en un trabajo en colaboración que desarrollaron con los estudiantes de Artes Gráficas del Liceo La Joliverie. ${ }^{8}$ El proyecto se basó en prácticas colaborativas en todas las fases, desde la concepción hasta la producción de la obra, partiendo de una investigación en la que los alumnos de La Joliverie redescubrieron el pasado local por medio de entrevistas con los vecinos y buscando fotografías antiguas. Tras este proceso dedicado a profundizar en el conocimiento del barrio, seleccionaron algunas de las principales señas físicas y simbólicas de la identidad del vecindario, que acabarían configurando la composición con el título irónico de La Fresqu 'île de Nantes, un juego de palabras que mezcla la noción de península y de mural al fresco ${ }^{9}$ (Figura 5). Los estudiantes de arte y diseño de La Joliverie también realizaron la cartela en la que se identifica el mural y se explica a los paseantes los detalles iconográficos y el mensaje que contiene esta gran obra colectiva. ${ }^{10}$ En muchos sentidos, sería un ejemplo emblemático de lo que algunos teóricos del arte público han dado en llamar obra "antena" con la cual la comunidad local se representa y se interroga (Mancini, 2011, p. 71).

Como se ve, en el street art en general pero muy particularmente entre los protagonistas del arte urbano en Nantes se ha desarrollado una enorme evolución en pocas décadas, desde el tag con la obsesiva firma personal de sus inicios hasta el muralismo colectivo floreciente en el momento actual, cuando en lugar de la identidad autoral individual se propugnan diversas formas de co-autoría. Esa tendencia ya despuntaba en la primera edición del programa de Le Voyage à Nantes en el verano de 2012 cuando el colectivo Pick Up Productions unió esfuerzos con Plus de Couleurs para desarrollar un encuentro al que denominaron Over the Wall: Histoires de graffiti en el que tomaron parte cerca de treinta creadores de diversas procedencias. Desde entonces se han multiplicado las prácticas colaborativas entre los propios muralistas y con la gente. Incluso se busca construir una iconografía y narrativas visuales en conexión con la memoria e imaginario colectivo de los vecinos. Quizá esto sea un retorno a las iniciativas sociales para las que se acuñó en otro tiempo en inglés la designación community arts, aunque aquello más bien solía tratarse de una práctica amateur resultante en anónimos murales pintados colectivamente 
por gente de alguna barriada (Scher, 2007).

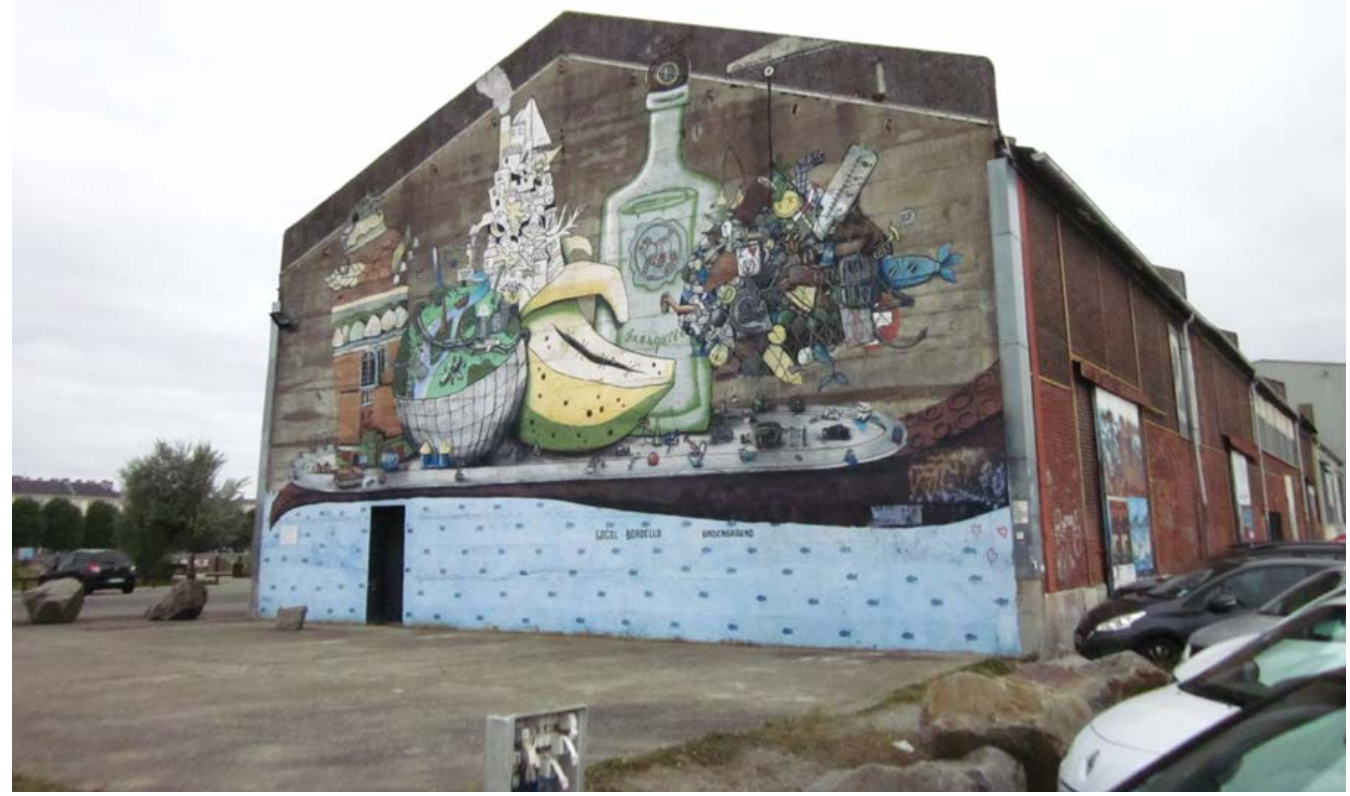

Figura 5. El mural Fresqu 'île de Nantes ubicado en una antigua nave industrial entre el hangar 32 y La Cantine en el distrito cultural de Nantes. Foto: Natalia Juan.

Más bien, habría que describir las tendencias actuales en relación con acciones de "artivismo" en espacios públicos, para las que algunos autores reivindican la etiqueta de "arte público" en el más pleno sentido de la expresión, cuando los artistas trabajan en colaboración con los propios ciudadanos que serán su público habitual, a menudo con la complicidad especial de estudiantes de arte en centros educativos de la zona (Remesar, 1999). Otros casos ejemplares podrían ser los diversos talleres impartidos desde 2014 a 2019 por el colectivo 100 Pression en la Universidad de Nantes, abiertos a su alumnado para realizar murales colectivos dentro de las instalaciones de la universidad. ${ }^{11}$ Es un compromiso vocacional de cooperación con la comunidad muy desarrollado entre los nombres más ilustres del arte urbano de Nantes, como el artista conocido como Ador -nombre que responde al acrónimo de Attrapé, Délaissé, Oublié, Rejecté; esto es, Atrapado, Abandonado, Olvidado, Rechazado- cuyas ideas sobre arte colaborativo han sido magníficamente articuladas en algunas entrevistas. ${ }^{12}$ Pero sin duda su espíritu de camaradería e involucración social se han visto estimulados por la densa red de complicidades generadas por la convivencia en el distrito cultural de l'île de Nantes, un ecosistema creativo que ha actuado como catalizador de la colaboración de asociaciones, colectivos y estudios.

Para fertilizar ese feraz territorio cultural, SAMOA ha implementado un sistema integral de asesoramiento y apoyo a los artistas $u$ otros agentes de industrias creativas cubriendo todas 
las etapas del trabajo, desde el apoyo económico, pasando por la planificación de actividades hasta llegar a programas de innovación para llevarlas a cabo. Su proyecto estrella es la Creative Factory, que a partir de 2023 funcionará en las naves industriales Halles Alstom, reconvertidas en talleres de artistas e informáticos, u otros servicios educativos y culturales por el arquitecto Franklin Azzi. ${ }^{13}$ Esa "fabrica" creativa vendrá a complementar a la que ya protagoniza otro hub cultural en l'île de Nantes, La Fabrique: laboratoire(s) artistique(s), entidad municipal creada en 2009, cuyo icónico doble edificio en el Quartier de la Création fue inaugurado el 30 de septiembre de 2011 como sede de la asociación Trempolino y otros colectivos artísticos (Gracelaine, 2010, p. 57-59; 2011, p. 29-32). ${ }^{14}$ En tanto que beneficiarios de subvenciones públicas, una de sus líneas prioritarias de actuación es desarrollar la organización y gestión de proyectos culturales y/o educativos donde adquieran especial importancia diversas formas de co-laboración.

Con el uso de guion de separación queremos dar una traducción literal a la expresión inglesa co-working, que usan a menudo en Francia para referirse a establecimientos en donde trabajan en contigüidad artistas, arquitectos, diseñadores, u otros creativos compartiendo talleres, oficinas $u$ otros espacios. Se considera una convergencia laboral simbiótica con beneficios para ellos mismos y también para la ciudad, pues su presencia otorga al vecindario un aire boho chic, que lo hace especialmente atractivo, según las teorías de Richard Florida sobre la "clase creativa", que también han tenido mucho eco en Francia, aunque con intensas controversias entre partidarios y detractores (Florida, 2002; Vivant, 2009; Pilati y Tremblay, 2010; Pignot, 2010). Esa convicción justifica las ayudas municipales a otras plataformas gestionadas por asociaciones e iniciativas privadas, como es el caso de Norkiouse Arts, asociación fundada en 2016 para ayudar a los artistas a organizar exposiciones, eventos o encuentros, particularmente de escultura. Desde 2018 está ubicada en el número 20 del Boulevard de la Prairie, esto es, en pleno corazón de la île de Nantes, compartiendo sede con el espacio artístico Mékano y con Le Triphasé, un taller de artistas y lugar de exposiciones creado por el artesano enmarcador Franck Moinel para apoyar tanto oficios artísticos y arte tradicional como manifestaciones de arte contemporáneo. También incentiva el co-working artístico y su difusión social otra asociación muy activa llamada La Conciergerie: una sociedad cooperativa nacida en 2012 para animar la vida de barrio ofertando talleres de serigrafía e iniciativas de arte comunitario, que en 2016 abría su primera sede, La Conciergerie du Front Pop y en 2018 La Conciergerie du Parc, en frente de la grúa amarilla ${ }^{15}$.

Idénticas sinergias son también patrocinadas por el Ayuntamiento de Burdeos, que subvenciona a los emprendedores que trabajan codo a codo en la Pépinière éco-créative des Chartrons ${ }^{16}$. Estas instancias de convivialidad socio-artística que combinan iniciativa pública y privada, son desde luego una apuesta reconocida por la economía creativa como motor del desarrollo de Burdeos. Algunas también se han convertido en experimentos sociopolíticos sobre cómo mantener esa vivificadora presencia de artistas y activistas cuando llega la gentrificación; por ejemplo, en el distrito de Chambrons donde el mercado inmobiliario ya les hubiera expulsado de no ser por esta red de espacios de co-working y la existencia de agrupación de talleres para artistas (Tapie, 2011).

Tampoco se cobra alquiler ni a los artistas ni a la mayoría de las empresas que están llenando de vida el antiguo cuartel Darwin, clausurado definitivamente en el año 2005. Una zona degradada al otro lado del río Garona que no resultaba atractiva para los bordeleses, habitualmente poco motivados para cruzar el decimonónico Pont de Pierre y llegar al barrio de la Bastide. Por eso se decidió desarrollar un invernadero de empresas y emprendedores, liderado por el 
arquitecto Philippe Barre, a quien en el año 2009 el ayuntamiento de Burdeos le vendió algunos almacenes. Esta iniciativa mixta llegó a su cénit a partir de 2013, cuando se creó Darwin como espacio cultural. Los dos enormes edificios militares forman hoy en día una sucesión de espacios co-working, start-ups tecnológicas, consultores, talleres de artistas, diseñadores y agencias creativas. Las antiguas edificaciones militares quedan unidas entre sí por la instalación Vortex de Pierre Schneider y François Wunschel: una especie de puente de madera sostenido por una estructura metálica recorrido por venas eléctricas por las que corren halos de luz (Figura 6). Bajo esta pasarela se encuentra el Magasin General de sello ecológico y la magníficamente bien nutrida librería Géolibri. Darwin es además el epicentro del street art de todo Burdeos, invadido de arte mural urbano en los ejemplares de Tétrodon que han quedado en estas instalaciones. Así aquellos módulos creados en los ' 60 por los diseñadores bordeleses que hicieron furor en su momento, han sido dotados de un nuevo uso al transformarse en talleres para artistas e ilustradores y recubiertos de impresionantes grafitis.

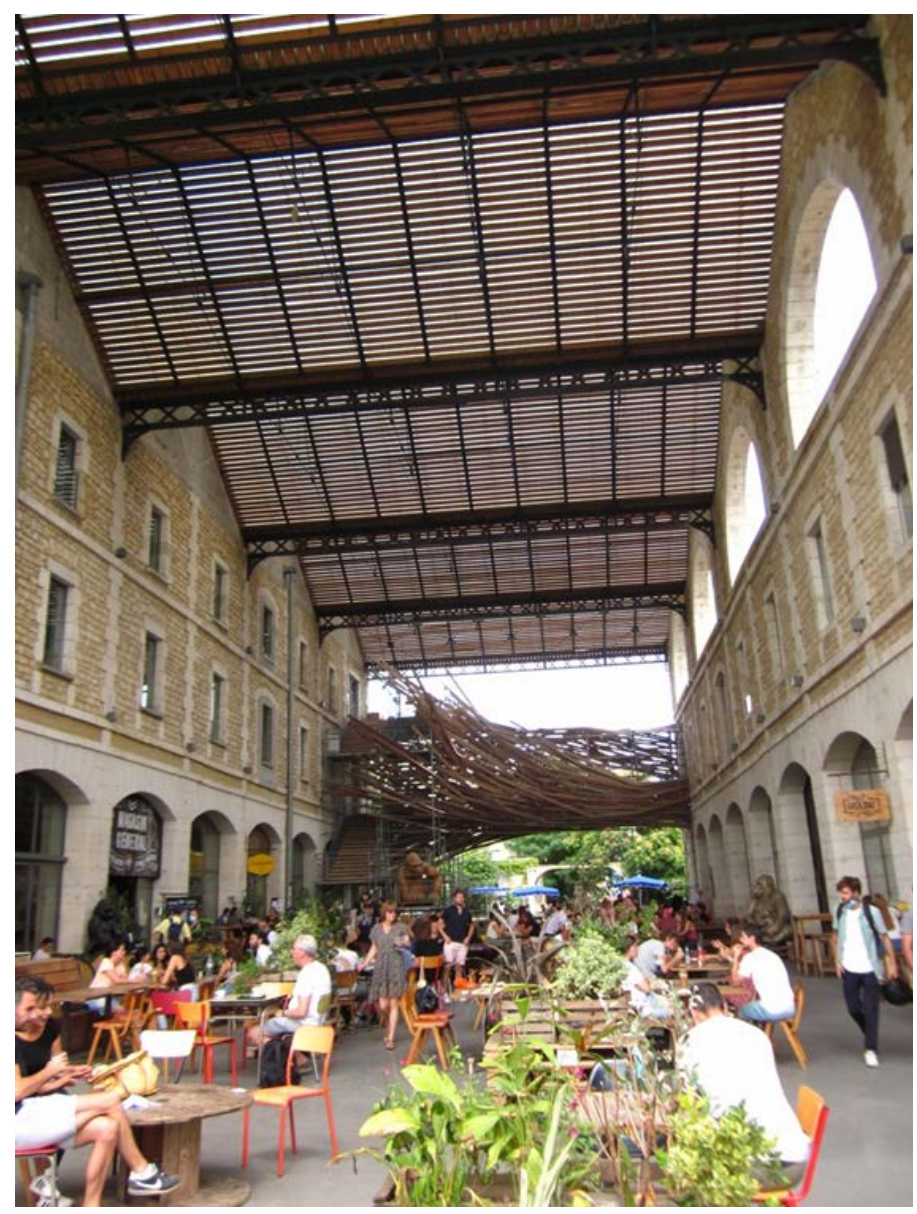

Figura 6. La instalación Vortex de Pierre Schneider y François Wunschel en el recinto Darwin de Burdeos. Foto: Natalia Juan. 
Pero sobre todo la animación de Darwin se debe a que tiene como vecinos de enfrente a todos los creadores que ocupan las antiguas instalaciones industriales de la fábrica Pola (Figura 7). Un total de 24 organizaciones, autónomas en el desarrollo de sus propios proyectos, que ayudan a incentivar las artes visuales. Se trata de un equipamiento cultural dedicado a la organización profesional de las artes visuales, basado en valores de economía circular y solidaria. La reconversión de la Fabrique Pola en un centro de estas características fue impulsada por y para las comunidades de artistas, siguiendo los precedentes de otras friches creativas en Francia y el resto de Europa (Andres y Gresillon, 2011). Su propósito es promover el consumo de arte en la vida cotidiana de los habitantes en la relación con el territorio. Entienden el arte no sólo como resultado si no como un proceso social. La Fabrique Pola es una cooperativa basada en los conocimientos de las estructuras culturales y en la experiencia de los artistas para construir recursos profesionales y ofrecer servicios de asesoramiento para la puesta en marcha de proyectos creativos vinculados con el campo del arte contemporáneo, la arquitectura, el mundo editorial, el gráfico, la ilustración, el universo digital, el audiovisual y la ingeniería cultural. De este modo, en Burdeos además del veterano Chartrons, la regeneración urbana juvenil está floreciendo en otro distrito cultural, en La Bastide, aunando el arte mural con la arquitectura contemporánea de los nuevos hangares del tranvía, el archivo municipal o el jardín botánico, un parque en el que las plantas conviven con módulos, pequeñas construcciones y parterres creados por los mejores diseñadores de la ciudad.

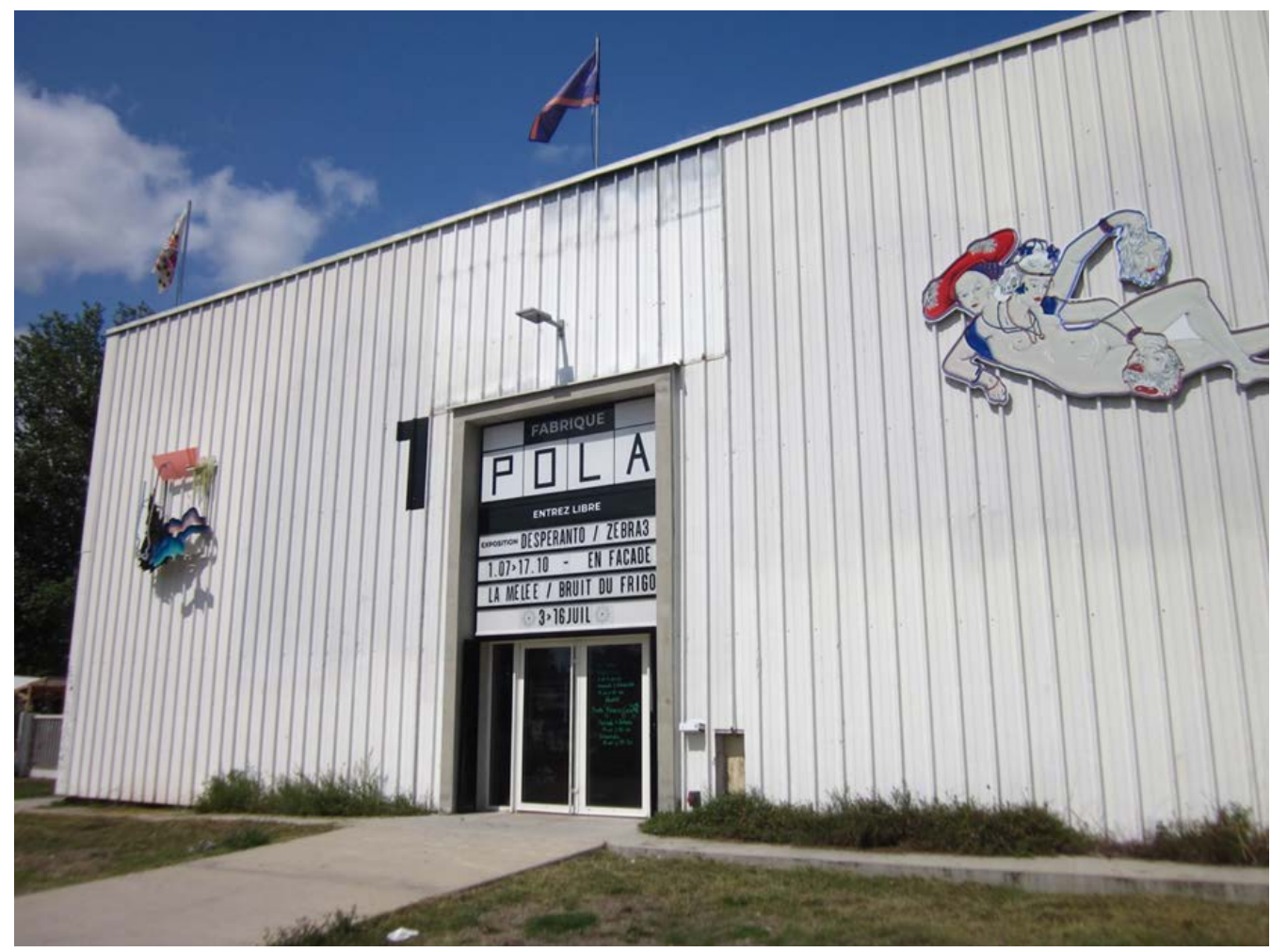

Figura 7. La fábrica Pola de Burdeos en el regenerado distrito de La Bastida en Burdeos. Foto: Natalia Juan. 
No solo las icónicas arquitecturas, monumentos e instituciones configuran la identidad de un distrito cultural; también hay que tener muy en cuenta el "factor personal", la intensa actividad de un tejido social en el cual los artistas y su ecosistema humano se hacen notar. Sobre todo si sus prácticas artísticas relacionales dan al barrio una imagen cool, integrando la alta cultura institucional con iniciativas populares de base. Se trata de una apuesta de revitalización urbana cuyo desarrollo es menos espectacular y mucho más lento que el del fulgurante "milagro Guggenheim", aunque últimamente incluso en Bilbao lo han adoptado también; especialmente tras crearse a partir de 2015 la designación "Isla Creativa" por la Comisión Gestora de Zorrotzaurre, el proyecto que continúa la regeneración urbana en la ría, pero con mayor cooperación horizontal ${ }^{17}$ que cuenta con su propia Fábrica de Industria Cultural y Creativa denominada La Terminal. FICC. Ese giro en la política cultural y social es el resultado de la progresiva concertación entre los poderes públicos, instituciones mixtas e iniciativas privadas; una forma de actuar para la que probablemente hayan servido como referente las políticas culturales ensayadas en Burdeos y Nantes u otras ciudades pioneras en esa estrategia. En efecto, en la costa atlántica francesa habían ido cobrando notoriedad a lo largo de las últimas tres décadas plurales iniciativas artísticas de interacción social, propiciando una proactiva interrelación entre el sector artístico y la población. Gracias a ellas, sus distritos culturales han alcanzado una favorable visibilidad pública como escenarios de creatividad/democracia participativa y colaborativa, aunando las iniciativas e ideas de arquitectos, diseñadores, urbanistas, paisajistas, políticos, sociólogos, miembros de asociaciones vecinales y artistas.

\section{CONTRIBUCIÓN AUTORES}

Idea: N.J.G y J.P.L.; Revisión de literatura (estado del arte): N.J.G y J.P.L.; Metolodogía (estudio de campo): N.J.G.; Análisis de Resultados: N.J.G y J.P.L.; Discusión y conclusiones: N.J.G y J.P.L.; Redacción: N.J.G y J.P.L.; Revisiones finales: N.J.G y J.P.L.

\section{APOYOS}

Este artículo se enmarca en el proyecto 'Distritos culturales de museos, galerías, establecimientos y paisajes urbanos patrimoniales' sufragado por el Ministerio de Ciencia, Innovación y Universidades (ref. PGC2018-094351-B-C41). Sus IPs son Jesús Pedro Lorente Lorente y Natalia Juan García, miembros del Instituto de Patrimonio y Humanidades de la Universidad de Zaragoza y del grupo Observatorio Aragonés de Arte en la Esfera Pública (OAAEP), financiado por el Gobierno de Aragón con fondos FEDER. 


\section{REFERENCIAS}

Andres, L. y Grésillon, B. (2011). Les figures de la friche dans les villes culturelles et créatives. Regards croisés européens, L'Espace Géographique, 1, 15-30.

Bishop, C. (2012). Artificial Hells. Participatory Art and the Politics of Spectatorship, Londres: Verso Books.

Bourriaud, N. (2008). Estética relacional. Buenos Aires: Adriana Hidalgo ed.

Florida, R. (2002). The Rise of the Creative Class, And How It'sTransforming Work, Leisure,Community and Everyday Life, NewYork: Basic Books.

Gravelaine de, F. (2010). Les Machines, la Fabrique, Le temps du projet. Nantes: Samoa, Place publique.

Gravelaine de, F. (2011). Fabrique: un projet de territoire plus qu'un équipement, La création prend ses quartiers. Nantes: Samoa, Place publique.

Grau Tello, M. L., Juan García, N. y Lorente Lorente, J. P. (2020). Street art en el distrito creativo de l'île de Nantes: Pinturas murales como anclas de identidad y memoria. En José Prieto (ed.) Arte y memoria V. Teruel: Fundación Universitaria Antonio Gargallo y Tervalis, 19-40.

Juan García, N. (2016). Barrios artísticos con un pasado monástico. Su transformación urbana en distritos culturales. En Chaves Martín, M. A., y Lorente, J. P., (eds.). Barrios Artísticos y distritos culturales: nuevos espacios para la creatividad y la revitalización urbana. Madrid: Icono 14 Editorial, 129-162.

Juan García, N., Grau Tello, M. L. y Lorente Lorente J. P. (2020). Arte participativo y colaborativo en el espacio público de Nantes: Una galería a cielo abierto con doble involucración social y terminológica, Umática: revista sobre creación y análisis de la imagen, 3, 71-93.

Mancini, M. G. (2011). L'arte nello spacio pubblico. Una prospettiva critica. Salerno: Plectica.

Nicolas, A. y Roy, E. (2015). La "clusterisation" du projet urbain de l'ile de Nantes. Nantes: CRENAU, Centre de Recherche Nantais Architectures Urbanités. 
Pignot, L. (2010). La ville créative: concept marketing ou utopie mobilisatrice? L'Observatoire, la revue des politiques culturelles, 36, 23-24.

Pilati, T. y Tremblay, D. G. (2010). Cité créative et district culturel. Des interelations entre deux concepts? En Tremblay, Rémy y Tremblay, Diane-Gabrielle (dirs.) La clase créative selon Richard Florida. Un paradigme urbain plausible? Rennes-Quebec: PURPUQ, 127-148.

Remesar, A. (1999). Arte contra el pueblo: tensiones entre la democracia, el diseño urbano y el arte público. Barcelona: Universitat de Barcelona.

Scher, A. (2007). Can the arts change the world? The transformative power of community arts, New Directions for Adult and Continuing Education, 116, 3-11.

Tapie, G. (2011). Bordeaux, économie de la connaissance et de la créativité. Popsu 2.

Violeau, J. L. (2016). L'île de Samoa à Nantes. Nantes: Éditions B2.

Vivant, E. (2009). Qu'est-ce que la ville créative? París: Presses universitaires de France. 
1. Se trata de un cluster de industrias creativas en Nantes y su espacio metropolitano (Nicolas \& Roy, 2015), pero especialmente en el Quartier de la Création de l'île de Nantes, donde tiene la sede de sus oficinas, ubicadas en el Bâtiment Eureka, 1 Mail du Front populaire, 44202 Nantes, France https://www.iledenantes.com/operations/eureka/ (Fecha de consulta: 10/09/2021).

2. Tal designación, de inspiración anglosajona, tenía por lo demás el valor de servir para delimitar o diferenciar una zona, para definirla nominalmente, incluso en la señalética urbana. Véase https://www.iledenantes.com/quartier/quartier-de-la-creation/ (Fecha de consulta: 10/09/2021).

3. Sobre su labor creadora véase http://www.lamachine.fr/francois-delaroziere/ (Fecha de consulta: $26 / 11 / 2021)$.

4. Página web oficial de las Machines de l'île https://www.lesmachines-nantes.fr/decouvrir/ la-galerie-des-machines/ (Fecha de consulta: 10/09/2021).

5. SAMOA ha pilotado la enorme transformación de l'île de Nantes logrando evitar la gentrificación elitista y fomentando la sociabilidad con áreas de pic-nic, huertos urbanos, barbacoas vecinales y una gran variedad de infraestructuras y espacios públicos (Violeau, 2016). Se ha construido gran número de viviendas familiares de todo tipo y apartamentos para estudiantes, oficinas, tiendas y áreas de negocios o centros culturales y zonas verdes. Véase https://www.iledenantes.com/operations (Fecha de consulta: 10/09/2021).

6. La Fondation Desperados pour l'Art Urbain se creó en 2018 como consecuencia de la colaboración durante más de 20 años con el colectivo 9ème. Su objetivo es la promoción del arte urbano contemporáneo en la sociedad y el apoyo a artistas emergentes favoreciendo el intercambio y creando sinergias innovadoras. La Fondation Desperados pour l'Art Urbain se articula en torno a la promoción y difusión del arte urbano. Ver https:// fondationdesperados.com/ (Fecha de consulta: 10/09/2021).

7. Para conocer las actividades y colaboraciones artísticas que se desarrollan en esta Escuela véase http://www.bordeaux.archi.fr/ (Fecha de consulta: 10/09/2021).

8. Centro educativo artístico instalado en el Quartier de la Creation desde 2010: este polo de artes gráficas actuó como promotor y financiador del proyecto. No es ésta su única vinculación con estas iniciativas artístico-sociales. En 2018, dentro de los Proyectos Pedagógicos que desarrolla La Joliverie, los alumnos del Centro de Artes Gráficas y Studio Katra volvieron a colaborar en la realización de un nuevo mural en la rue d’Ancin.

9. Su variopinto programa pictórico pasa revista a una amplia panorámica del pasado y del futuro soñado por los jóvenes para su ciudad revisando algunos de sus iconos visuales. Para conocer en más detalle la iconografía y significado del mural, se remite a la lectura del artículo publicado por el propio centro promotor de la obra https://www.la-joliverie.com/ actualites/762-une-fresqu-ile-avec-ador.html (Fecha de consulta: 10/09/2021). 
10. Entre sus protagonistas iconográficos cabe citar a Julio Verne, evocado a través del brazo del pulpo de 20.000 leguas de viaje submarino, o la característica torre de la fábrica de LU -hoy sede de Le Lieu Unique- recreada como un llavero-edificio - un guiño a la idea del souvenir y la turistificación- hecho a partir de sus características galletas de mantequilla -petit beurres, de los berlingots nanteses o de flora local típica como el muguet. Junto a la torre de LU, aparece una esfera de contrastes, que en su parte inferior es una bola de discoteca y en la superior se representa como una imagen de Nantes, donde se concentran elementos del pasado -el barco Belem, la grúa amarilla- y del presente y futuro de una ciudad en crecimiento -la industria aeronáutica o la ciudad verde-. Otra alusión a historia y el porvenir de Nantes vuelve a aparecer también en la gran banana que preside el centro de la composición, en referencia al pasado comercial de Nantes y al almacenaje de productos de ultramar que en otro tiempo tuvo lugar en este entorno de la île, mientras que la botella alude a la ciudad deseada para las generaciones venideras.

11. Recuperado de https://www.univ-nantes.fr/s-epanouir-sur-les-campus/

fresque-collective-I-artiste-ador-investit-le-campus-yonnais-pour-une-deuxieme-

annee--2490750.kjsp?RH=1579599204058 (10/09/2021). Otro ejemplo más cercano en el tiempo es el ideado para el convulso curso académico 2020-2021. A pesar de las circunstancias sanitarias, la Universidad de Nantes ha seguido con la formación práctica y activa en temas de arte urbano, realizando un mural en el campus de la Roche-sur-Yon, desde el 17 de septiembre de 2020 hasta el 31 de enero de 2021, entre los alumnos y el artista Ador.

12. Resulta de interés leer las entrevistas realizadas a Ador porque permiten conocer sus ideas sobre el trabajo en equipo. Recuperado en http://www.skin-artists.com/interviewwith-ador.htm y https://www.artistup.fr/articles/581/ador-la-recherche-du-contrairevers-un-resultat-fleurissant (09/09/2021). Además, este vídeo sobre su proceso de trabajo https://www.youtube.com/watch?v=zvHb166gAU4

13. Será el corazón del Quartier Créatif, al lado de la École des Beaux-Arts, el Pôle universitaire interdisciplinaire des cultures numériques, la Nantes Tech, y el Food Hal, según se indica en https://www.creativefactory.info/

(Fecha de consulta: 10/09/2021).

14. Cinco asociaciones nantesas han participado en la realización del proyecto desde su origen: apo33, Mire, microfauna, Trempolino y Songo. A ellas se suman desde 2009 nuevas asociaciones, que han llegado con la apertura de la fábrica Dervallières, y parte del proyecto colectivo La Luna -artes plásticas-, Frascos -coalición de instrumentistas compositores-, Yolk -jazz-, Le Dernier spectateur -escritura-, Fragil -webzine cultural-, charla producciones -creación transdisciplinaria-, V.I.A.: Virus de Interés Artístico desarrollo de artistas-, Spoutnik Théâtre Production -producción de teatro alternativo y comprometido- y la Compagnie Chute Libre -dirección de la cultura hip hop-. El conglomerado tuvo tanto éxito que en seguida se optó por diversificar ubicaciones, así que, en 2012, La fabrique creó otras dos sedes en otros tantos distritos: DervallièresZola y Bellevue-Chantenay-Sainte Anne.

15. Sobre las actividades que se desarrollan en La Conciergerie, véase https://www. laconciergeriedequartier.fr/ (Fecha de consulta: 10/09/2021). 
16. Sobre las empresas y actividades en este espacio dedicado a la economía creativa y a la innovación y digital véase https://www.pepiniere-chartrons.fr/ (Fecha de consulta: 10/09/2021).

17. Se trata de conferir a este enclave depauperado una serie de equipamientos que van desde la vivienda accesible, la presencia de áreas empresariales, la dotación de equipamientos públicos -que ya se están implementado de manera no oficial- así como de amplias zonas de uso ciudadano. Véase https://www.zorrotzaurre.com/isla-creativa/ (Fecha de consulta: 26/07/2021). 